\title{
ЦЕНТР КОЛЛЕКТИВНОГО ПОЛЬЗОВАНИЯ НАУЧНЫМ ОБОРУДОВАНИЕМ ТГУ ИМЕНИ Г.Р.ДЕРЖАВИНА: ВОЗМОЖНОСТИ И ПЕРСПЕКТИВЫ
}

\section{CENTER FOR COLLECTIVE USE OF SCIENTIFIC EOUIPMENT IN DERZHAVIN TAMBOV STATE UNIVERSITY: OPPORTUNITIES AND PROSPECTS}

\author{
А.А.Дмитриевский, д.ф.-м.н., дощент, (ORCID: 0000-0001-7342-4638) / aadmitr@yandex.ru \\ A.A.Dmitrievsky, Doct. of Sc. (Physics and Mathematics), Docent
}

DOI: 10.22184/1993-8578.2020.13.2.100.105

Получено: 19.03.2020 г.

Непременное условие научного прогресса - достоверность результатов эксперимента, достигаемая использованием высокотехнологичного научного оборудования. Центры коллективного пользования научным оборудованием (ЦКП) - современные "точки доступа" к дорогостоящим исследовательским установкам. Что же могут предложить ЦКП вдали от мегаполисов?

An indispensable condition for scientific progress is the reliability of the experimental results achieved using high-tech scientific equipment. Centers for the collective use of scientific equipment $(\mathrm{CCU})$ are modern "access points" to expensive research facilities. What can the CCU offer far from megacities?

D се мы привыклик тому, что лучшие образовательные учреждения и научные организации, а, следовательно, и их структурные подразделения - Центры коллективного пользования научным оборудованием, или сокращенно ЦКП, расположены в крупных мегаполисах: Москве, Санкт-Петербурге, Новосибирске, Екатеринбурге и в некоторых других городах, количество которых, все же можно пересчитать по пальцам. Следовательно, потенциальным заказчикам научной продукции (качественных научных или диагностических исследований и испытаний, технических разработок, квалифицированной консультационной поддержки и пр.) необходимо ехать за сотни верст в столичные ЦКП? Или в "периферийных" вузах и НИИ встречаются конкурентоспособные ЦКП, готовые обеспечить заказчика не только широким перечнем услуг, но, главное, предоставить надежный и достоверный результат с объективной интерпретацией?

Из перечня 20-ти российских ЦКП с максимальной номенклатурой научного оборудования (всего в научно-технологической инфраструктуре России на март 2020 года зарегистрировано 613 ЦКП) мы выбрали Центр коллективного пользования научным оборудованием Тамбовского государственного университета имени Г.Р.Державина (12-ая позиция в рейтинге ЦКП). Его руководитель доктор физико-математических наук Александр Дмитриевский - в ходе проведенной им экскурсии по ЦКП ответил на наши вопросы.

Александр, как был создан и что собой представляет сегодня ЦКП ТГУ имени Г.Р.Державина? Официально Центр коллективного пользования научным оборудованием Тамбовского государственного университета имени Г.Р.Державина создан в декабре 2018 года путем реорганизации ЦКП "Нанохимия и экология", образованного на базе ТГу имени Г.Р.Державина в 2008 году. Сегодня оснащение ЦКП складывается из оборудования нескольких научно-исследовательских и образовательных площадок (структурных подразделений со своими научными школами) Державинского университета. В первую очередь, разговор идет об оборудовании и научных коллективах НИИ "Нанотехнологии и наноматериалы" (под руководством Заслуженного деятеля науки РФ, д.Ф.-м.н., проф. Ю.И.Головина), 

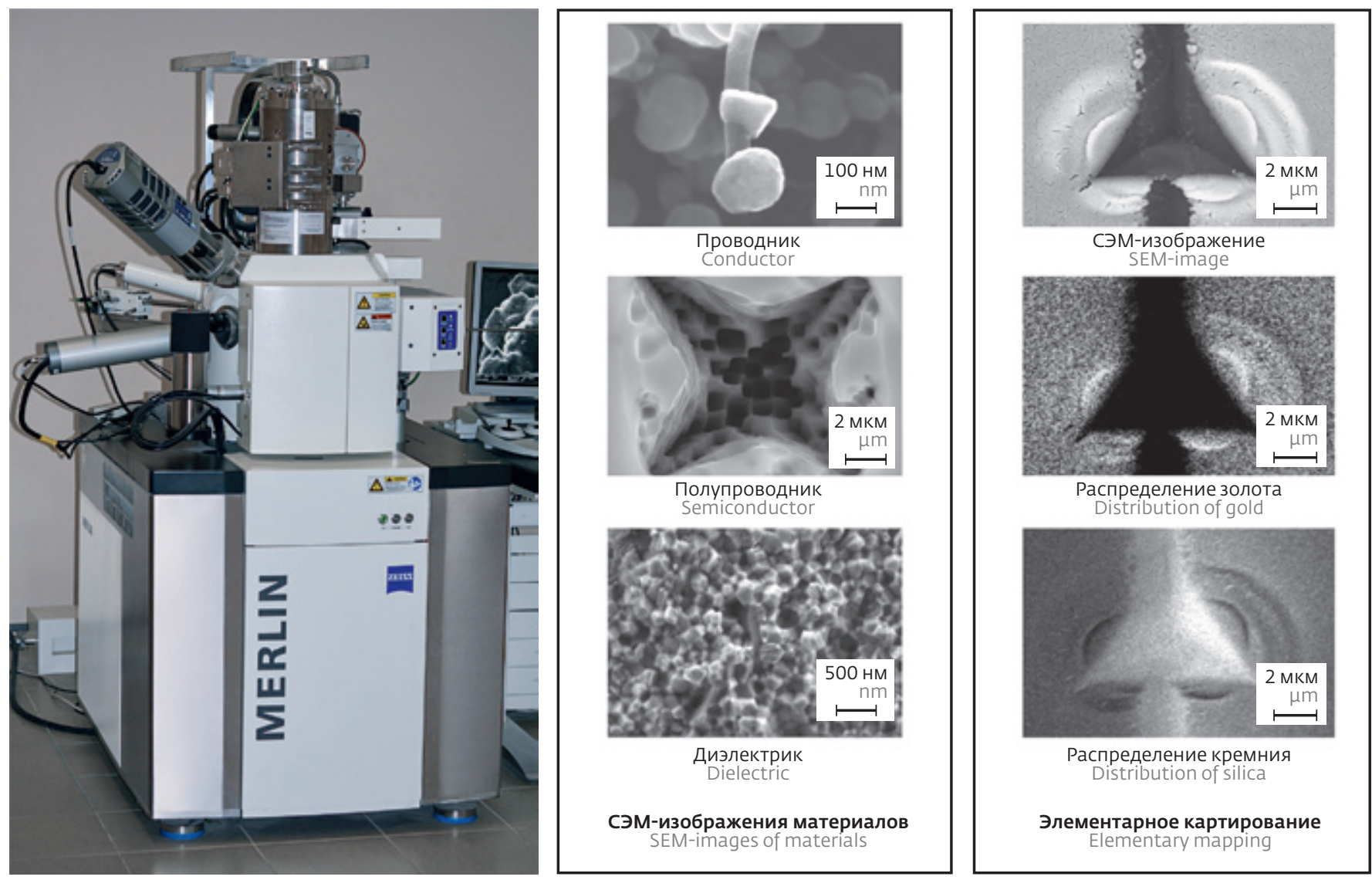

Puc.1. Фотография сканирующего электронного микроскопа высокого разрешения со спектрометрами Merlin (Carl Zеiss), СЭМ-изображения проводящих, полупроводниковых и диэлектрических материалов и пример элементного картирования участка поверхности образца

Fig.1. Image made of a high resolution scanning electron microscope with Merlin spectrometers (Carl Zeiss), SEM images of conductive, semiconductor and dielectric materials and an example of elemental mapping of a sample surface area

НИИ экологии и биотехнологий (под руководством д.б.н., доц. А.А.Гусева), НОЦ "Нелинейная динамика деформируемых твердых тел" (под руководством д.ф.-м.н., проф.А.А.Шибкова), НОЦ "Электрохимия конденсированных микро- и наносистем" (под руководством академика РАЕН (по секции нефти и газа) д.х.н., проф. Л.Е.Цыганковой), Испытательного центра ТГУ имени Г.Р.Державина (под руководством к.ф.-м.н., доц. А.В.Шуклинова), аккредитационно-симуляционного центра (под руководством к.м.н., доц. М.Л.Чернышевой), а также ряда научно-исследовательских лабораторий (под руководством ведущих ученых университета, научные интересы которых охватывают практически весь перечень естественных дисциплин от физики и химии до экологии и медицины). Приборная база ЦКП на сегодняшний день насчитывает более 90 единиц современного оборудования с общей балансовой стоимостью, превышающей 230 млн руб. Надежную работу оборудования, достоверность получаемых результатов и перспективность научных разработок обеспечивают десятки компетентных и высококвалифицированных ученых - сотрудников Державинского университета, многие из которых имеют богатый опыт работы в НИИ и на промышленных предприятиях.

Таким образом, ЦКП ТГУ имени Г.Р.Державина - это структура, располагающая внушительным арсеналом современного научного оборудования и высококвалифицированным кадровым составом и полностью отвечающая требованиям федерального закона относительно функционирования ЦКП. Стратегически мы нацелены на интеграцию и повышение эффективности взаимодействия интеллектуального потенциала наших ученых, приборной базы университета и инновационно-технологической среды производства для решения задач, определенных направлениями стратегии НТР РФ. При этом мы не оставляем без внимания ни одну заявку 


\section{2}

\section{РЕПОРТАЖ С ПРОИЗВОДСТВА}
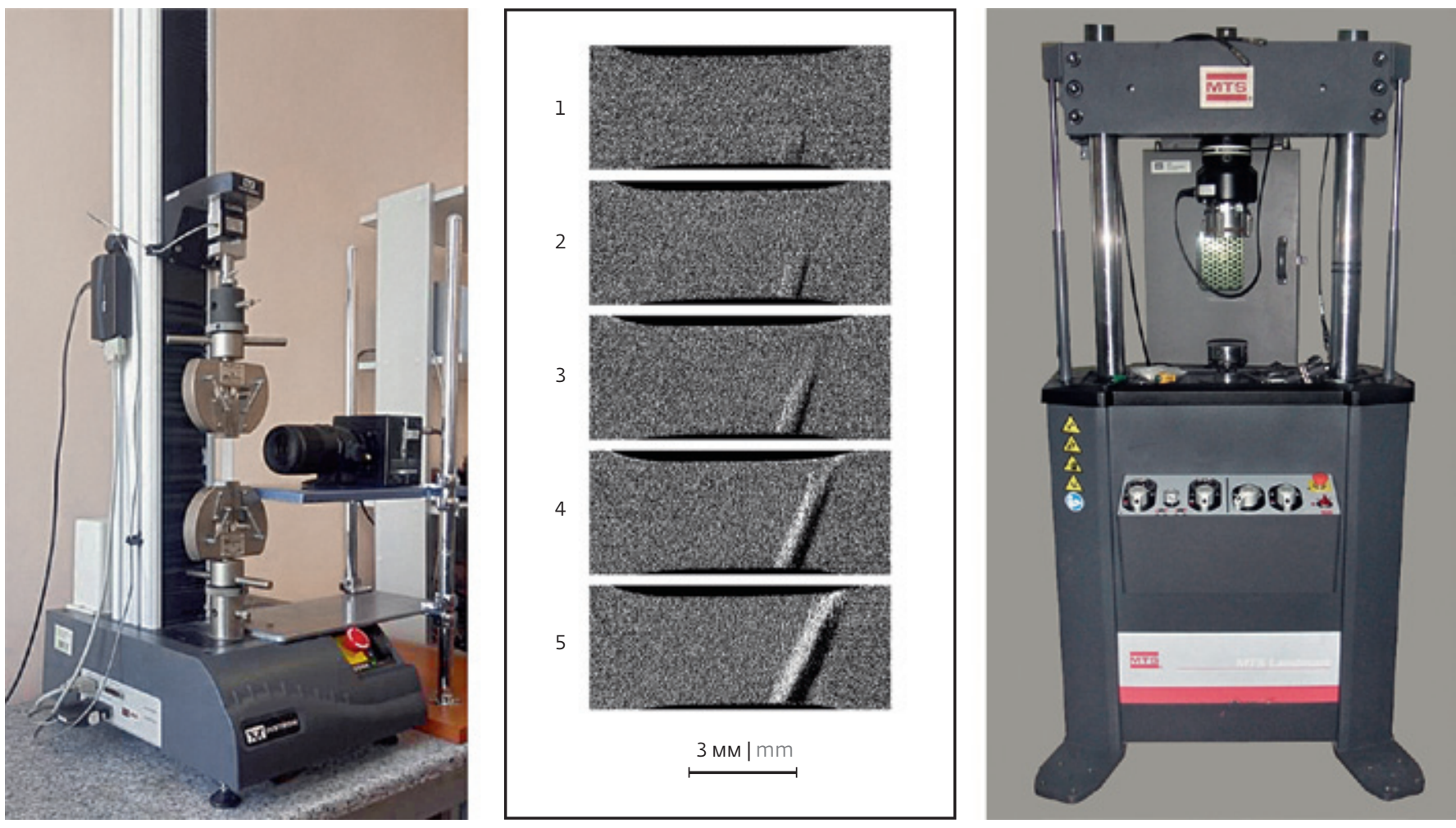

Pис. 2. Фотографии универсальной испытательной машины Instron 3344 с высокоскоростной камерой Photron FASTCAM Mini UX100 и напольной двухколонной сервогидравлической испытательной машины MTS 870 Landmark, a maкже кадры (полученные высокоскоростной камерой), визуализирующие развитие полосы деформации в металпическом образце при растяжении

Fig.2. Images of the Instron 3344 universal testing machine with the Photron FASTCAM Mini UX100 high-speed camera and the MTS 870 Landmark floor-mounted two-column servo-hydraulic testing machine, as well as frames (obtained by the high-speed camera), visualizing the development of the deformation band in the metal tensile

на оказание предлагаемых нами услуг вне зависимости от ведомственной принадлежности или от "статуса" заказчика.

Какие из услуг вашего ЦКП наиболее востребованы? Какое оборудование пользуется наибольшим спросом?

Прежде всего отмечу, что всех заказчиков наших услуг мы условно делим на две категории - "внутренние" и "сторонние". Практически все оборудование ЦКП достаточно интенсивно используется сотрудниками университета в рамках выполнения научно-исследовательской и образовательной деятельности. Поэтому трудно назвать оборудование, наиболее востребованное внутренними заказчиками (пользователями).

Сторонние заказчики чаще обращаются с задачами, связанными со структурными исследованиями материалов и диагностикой комплекса механических свойств. Пожалуй, наиболее востребованной является сканирующая электронная микроскопия. Сканирующий электронный микроскоп высокого разрешения со спектрометрами Merlin (Carl Zeiss) позволяет сотрудникам ЦКП исследовать объекты со сверхвысоким пространственным разрешением (до единиц нанометров) и высочайшим контрастом по материалу, а также (методом EDS) проводить элементный анализ материала и элементное картирование (визуализировать распределение химических элементов по исследуемому участку поверхности).

Кроме того, при проведении различного рода структурных исследований для сторонних заказчиков регулярно используем:

- рентгеновский дифрактометр D2 Phaser (Bruker AXS), предназначенный для проведения качественного и количественного анализа фазового состава, структурных характеристик, анализа степени чистоты и кристалличности порошков, включая системы, содержащие наноразмерные объекты; 
- анализатор площади поверхности и размеров пор Autosorb iQ-C (Quantachrome), предназначенный для определения пористости, удельной площади поверхности и среднего размера пор различных веществ: катализаторов, адсорбентов, керамик и других пористых материалов;

- анализатор размера частиц и дзета-потенциала Zetasizer Nano ZS (Malvern), предназначенный для измерения размера и дзета-потенциала коллоидных систем; определения размера, полидисперсности и дзета-потенциала наночастиц; а также для определения присутствия агрегатов, скрининга оптимальных условий для кристаллизации и исследования олигомеризации в сверхмалых объемах белковых сред.

Отдельного внимания заслу-
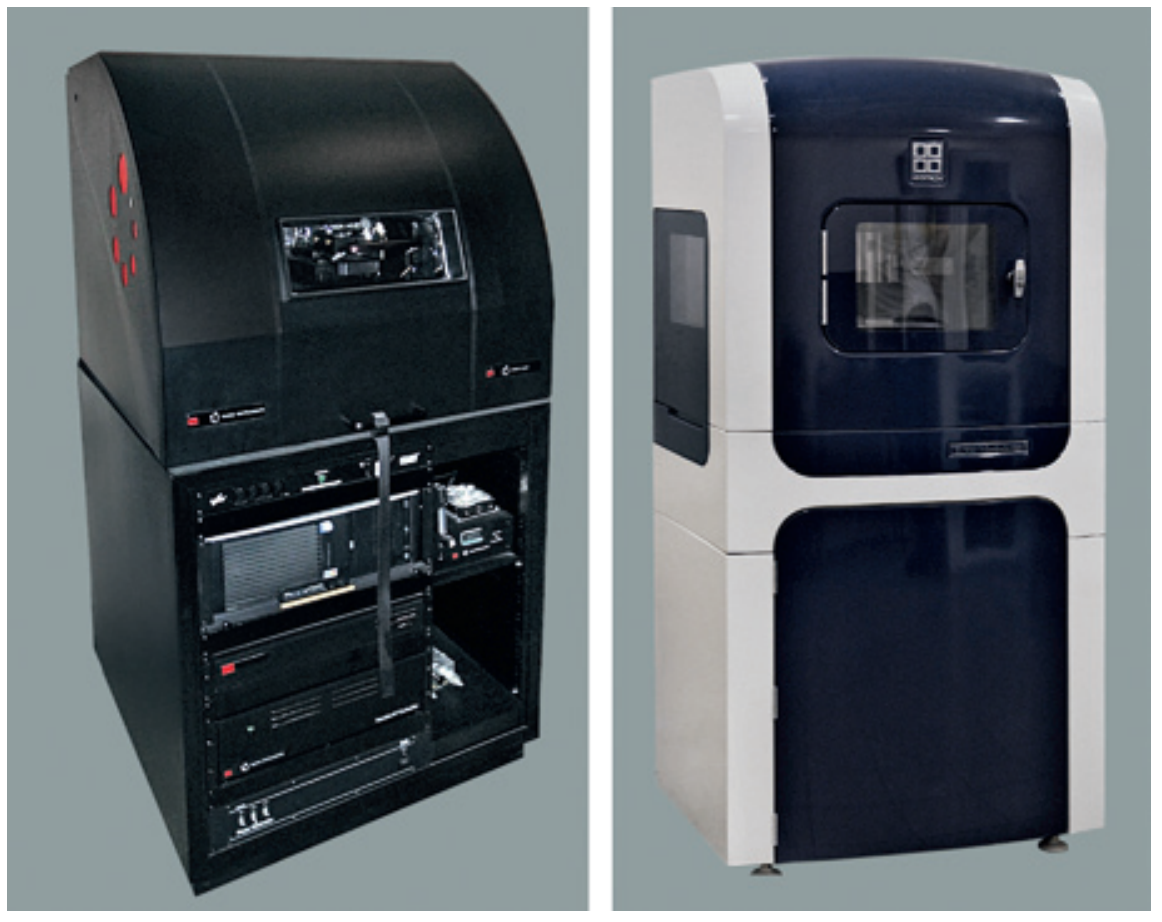

Puc.3. Фотографии наноидентометра Nanolndenter G200 (MTS Nanolnstruments) и нанотрибоиндентометра Triboindenter TI-950 (Hysitron)

Fig.3. Images of the Nanolndenter G200 nanoidentometer (MTS Nanolnstruments) and the Triboindenter TI-950 nanotriboindentometer (Hysitron)

живает широкая линейка обо-

рудования и методик ЦКП для диагностики и исследования механических свойств материалов на макро-, микро- и наноуровне. Для тестирования макромеханических свойств материалов мы предлагаем напольную двухколонную сервогидравлическую испытательную машину MTS 870 Landmark или универсальную испытательную машину Instron 3344. Последняя идеально подходит для проведения испытаний на растяжение или сжатие, рассчитанных на усилие меньше 2 кН. При этом процесс деформации материалов может фиксироваться высокоскоростной камерой Photron FASTCAM Mini UX100 с максимальной скоростью съемки до 200 тыс. кадров в секунду. Существенным преимуществом испытательной машины MTS 870 является ее универсальность, то есть возможность выполнить широкий спектр статических и динамических испытаний (растяжение, сжатие, изгиб, усталость, ползучесть и др.), при нагрузках до 50 кН. В этой системе реализуются режимы "мягкой" и "жесткой" испытательных машин. Также возможно исследование многоцикловой усталости материалов с максимальной частотой более 300 Гц. Специальный термостат позволяет проводить испытания в диапазоне температур от 25 до $315^{\circ} \mathrm{C}$.
Для диагностики микромеханических свойств материалов ЦКП располагает различными автоматическими и полуавтоматическими твердомерами, в том числе собственной разработки.

Предметом особой гордости ЦКП являются две установки для диагностики механических свойств на наноуровне: наноидентометр NanoIndenter G200 (MTS NanoInstruments) и нанотрибоиндентометр Triboindenter TI-950 (Hysitron). NanoIndenter G200 имеет функцию непрерывной регистрации значений (continuous stiffness measurements) модуля упругости и твердости в процессе наноиндентирования. При этом он имеет разрешение по смещению индентора 0,01 нм, а разрешение по нагрузке - 50 нН. Triboindenter TI-950, помимо измерения микро- и нанотвердости и модуля Юнга, позволяет определять коэффициент трения, исследовать ползучесть, адгезию пленок и покрытий, а также детально изучить механизмы деформации и разрушения материалов на различных иерархических уровнях. Его разрешение по нормальному смещению индентора - 0,02 нм, а разрешение нормальной нагрузки - 3 нН. Таким образом, мы имеем возможность проводить полный спектр наномеханических испытаний материалов посредством динамического индентирования. 


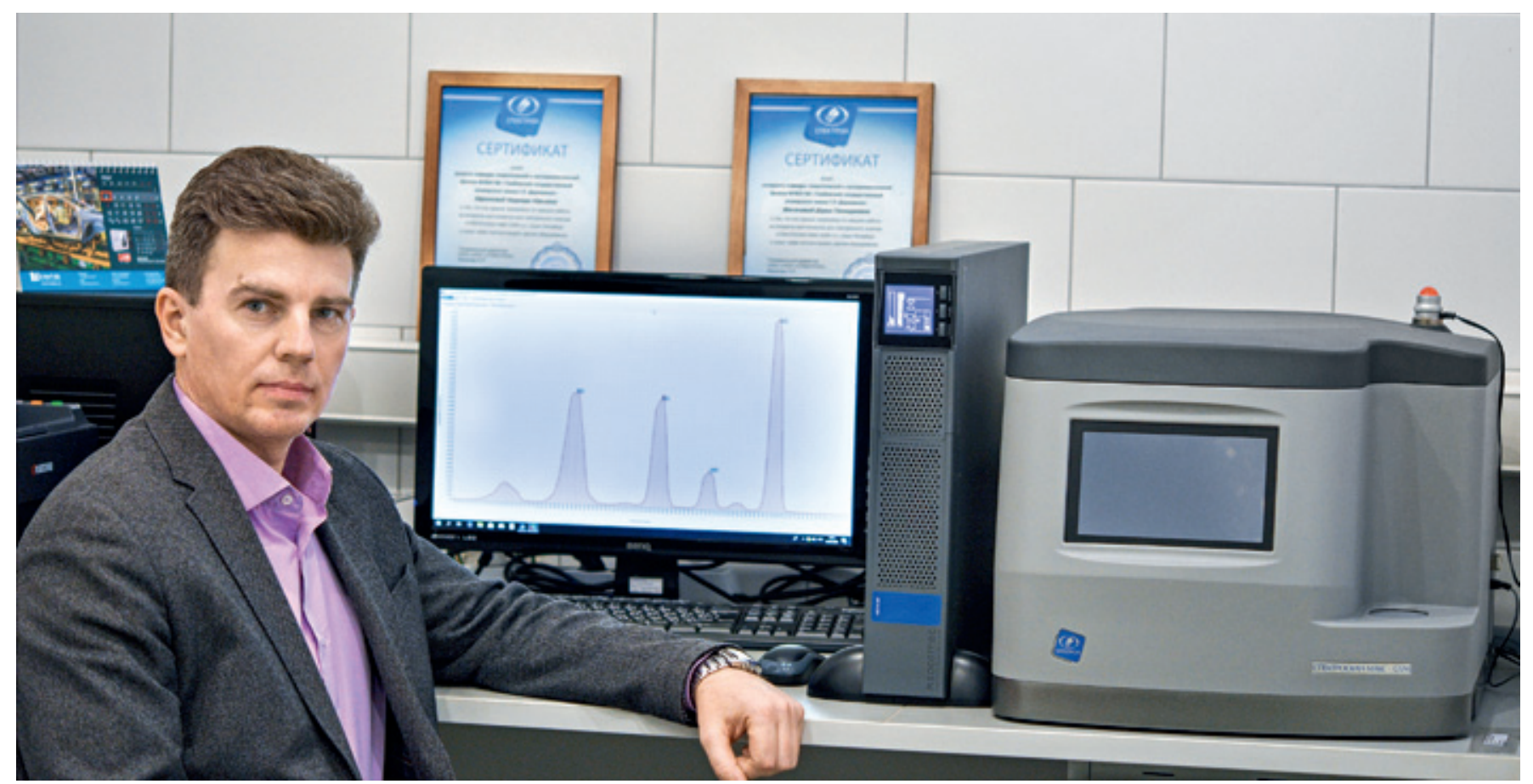

PUс.4. Комплекс на базе рентгеновского аппарата для спектрапьного анализа СПЕКТРОСКАН MAКС-GVM

Fig.4. Complex based on SPECTROSCAN MAX-GVM X-ray spectral analysis apparatus

Происходит ли расширение приборного парка и перечня оказываемых услуг ЦКП сегодня?

Пожалуй, наиболее масштабное расширение приборной базы началось с 2008 года, в рамках реализации Тамбовским государственным университетом имени Г.Р.Державина приоритетного национального проекта "Образование". Ежегодно парк высокотехнологичного оборудования пополняется за счет грантов и программ (РФФИ, ФЦП, РНФ, Госзадание и пр.), реализуемых научными коллективами университета. Это позволяет дооснащать действующие и организовывать новые научно-исследовательские лаборатории. Так, например, в 2019 году за счет средств Госсубсидии было приобретено оборудование для организации двух новых лабораторий (открытых в 2020 г.) лаборатории спектрального анализа и лаборатории молекулярно-генетических исследований.

Оборудование лаборатории молекулярно-генетических исследований позволит проводить самые различные виды ПЦР-анализа в реальном времени, включая качественное и количественное определение нуклеиновых кислот, генотипирование, анализ экспрессии генов, HRM-анализ (ДНК-амплификатор CFX96 BioRad); амплификацию нуклеиновых кислот (T100 Termal Cycler); захват и обработку изображений люминесцирующей ДНК в электрофорезных гелях (гельдокументирующая система Vilber E-Box-CX5) и пр.

Приобретенный для лаборатории спектрального анализа комплекс на базе рентгеновского аппарата для спектрального анализа СПЕКТРОСКАН MAKC-GVM (отечественного производства) расширит возможности ЦКП в части химического анализа материалов. СПЕКТРОСКАН MAKC-GVM позволяет на качественном и количественном уровне (методом рентгено-флуоресцентной спектрометрии) определять элементный состав (от ${ }^{11} \mathrm{Na}$ до ${ }^{92} \mathrm{U}$ ) различных материалов (твердых и сыпучих), а также жидких сред (фильтров).

Существенную поддержку в оснащении лабораторий, разумеется, оказывает и сам университет. В 2020 году на дооснащение лабораторий вспомогательным оборудованием из средств университета будет выделено более 6 млн руб. Кроме того, на 2020 год силами университета запланирована организация и оснащение специализированной научно-образовательной медико-биологической лаборатории.

Таким образом, арсенал высокотехнологичного исследовательского и диагностического оборудования ЦКП непрерывно расширяется. Следствием этого является пропорциональное расширение и перечня оказываемых услуг. 
Вы упомянули об оборудовании собственного производства. Не могли бы вы чуть подробнее осветить это направление деятельности?

Прежде всего отмечу, что у нас, как и в любом университете, каждая научная школа, каждое научное направление имеют свои разработки, подтвержденные соответствующими охранными документами. Поэтому вспомнить и перечислить все научно-технические разработки Державинского университета в одной беседе не представляется возможным. Коротко коснусь лишь основных научных коллективов и их достижений.

Коллективом НИИ "Нанотехнологии и наноматериалы" (под руководством проф. Ю.И.Головина) разработаны линейка приборов TOR для экспериментальной апробации магнито-наномеханического подхода к управлению биохимическими процессами низкочастотным магнитным полем; линейка приборов динамического наноиндентирования для определения физико-механических характеристик твердых тел в субмикрообъемах и тонких приповерхностных слоях (за разработку универсального динамического нанотестера Ю.И.Головин был удостоен Золотой медали ВВЦ); исследовательский комплекс для диагностики сыпучих, пористых наноматериалов и жидкостей; линейка инновационных приборов и методов тепловизионной инспекции и неразрушающего контроля изделий и конструкций; оборудование для магнито-импульсной обработки рудного сырья; техническое зрение - программноаппаратный комплекс экспресс-анализа железной руды и других многофазных материалов и мелких объектов; скретч-тестер для механических испытаний кернов горных пород; технологии синтеза наноструктурированной высокоплотной, пористой и волокнистой циркониевой керамики и пр.

Коллективом НИИ экологии и биотехнологий (под руководством доц. А.А.Гусева) разработаны способ экологически чистой молекулярно-клеточной фитоконверсии компонентов шламов металлургической индустрии; технология интенсивного восстановления лесов после пожаров способом применения наноструктурных стимуляторов роста и защиты древесных растений, полученных методом микроклонального размножения для минимизации негативных экономических эффектов лесных пожаров для лесозаготовительной отрасли и др.

Коллективом НОЦ "Электрохимия конденсированных микро- и наносистем" (под руководством проф. Л.Е.Цыганковой) разработаны: консервационные материалы для защиты металлоизделий от атмосферной коррозии; методики оценки универсализма ингибиторов сероводородной и углекислотной коррозии металлов; методы защиты от коррозии цветных металлов в средах и условиях эксплуатации спецтехники; и пр.

Это лишь несколько примеров разработок наших научных коллективов, большинство из которых к настоящему времени коммерциализированы. Несколько из перечисленных установок были разработаны и изготовлены по заказу ведущих отечественных и зарубежных научных лабораторий.

\section{Каковы конкурентные преимущества ЦКП ТГУ имени Г.Р.Державина?}

На мой взгляд, сразу несколько факторов выгодно отличают наш ЦКП среди прочих. Во-первых, базовой организацией нашего ЦКП является классический университет, что подразумевает широкий перечень развиваемых научных направлений. В совокупности с обширным разнообразием имеющегося оборудования это обеспечивает возможность оказания услуг, требующих междисциплинарных исследований. Во-вторых, наше географическое положение (г. Тамбов) оказывается привлекательным для заказчиков с достаточно большой территории, расположенной вдали от крупных научных центров. В-третьих, мы придерживаемся гибкой ценовой политики. При этом цены на наши услуги существенно ниже столичных, и, не смотря ни на что, мы удерживаем их практически неизменными на протяжении уже нескольких лет.

\section{Какие вы видите перспективы развития ЦКП} на ближайшие несколько лет?

Как я отметил выше, наша деятельность стратегически нацелена на активное участие в решении задач, определенных стратегией научно-технического развития РФ, на получение результатов, имеющих долгосрочные перспективы для новых наукоемких разработок и создания технологий, продуктов и услуг, отвечающих национальным интересам Российской Федерации.

Для этого ЦКП обязан непрерывно расширять (обновлять) материально-техническую базу; развивать кадровый потенциал; расширять сферу деятельности (перечень оказываемых услуг). Но, возможно, более важным шагом к достижению этой цели, будет являться создание коллабораций с ведущими научными центрами и, в перспективе, включение ЦКП ТГУ имени Г.Р.Державина в один из Научно-образовательных центров мирового уровня. 